\title{
Research on College Students' Safety Education Under the New Situation: Present Situation Investigation and Improvement Strategy
}

\author{
Yang Aixia ${ }^{1, \mathrm{a}}$, Fan $\mathrm{Xia}^{2, \mathrm{~b}}$, Yang Chaolin ${ }^{3, \mathrm{c}^{*}}$ \\ ${ }^{1}$ School of Foreign Languages and International Trade, Wuhan Polytechnic, Wuhan, Hubei, China \\ ${ }^{2}$ School of Mechanical and Electrical Engineering, Wuhan Polytechnic, Wuhan, Hubei, China \\ ${ }^{3}$ School of business, Wuhan Polytechnic, Wuhan, Hubei, China \\ aAlesha506@qq.com \\ b494183290@qq.com \\ c*442417390@qq.com
}

\begin{abstract}
Colleges and universities are the main source of human resource and very important places for college students to study and live. Campus security, stability and college and university students' safety have been highly valued by the party and the nation as well as the whole society. At present, many colleges still have problems such as imperfect safety education system and weak safety awareness among college students. Based on the investigation of more than 10,000 teachers and students in colleges and universities across the country, this paper analyzes the safety education situation of college students under the new situation, summarizes the problems existing in the safety education in colleges and universities, and puts forward countermeasures and suggestions to solve the problems, hoping to improve the effectiveness of safety education for college and university students effectively.
\end{abstract}

Keywords: college and university students, safety education, investigation, improvement strategy.

\section{新形势下高校大学生安全教育：现状调查及改进策略}

杨爱霞 ${ }^{1, a}$ 柇霞 $^{2,}$ b 杨朝林 ${ }^{3,}$ c*

1 武汉职业技术学院外语外贸学院, 武汉, 湖北, 中国

2 武汉职业技术学院机电工程学院, 武汉, 湖北, 中国

3 武汉职业技术学院商学院, 武汉, 湖北, 中国

aAlesha506@qq.com

b494183290@qq.com

c*442417390@qq.com

\section{摘要}

高校是人才培养的主阵地, 也是大学生学习生活的重要场所, 校园安全稳定和大学生安全一直以来受到党和国 家的高度重视和全社会的极大关注。但是目前很多高校还存在安全教育体系不健全、大学生安全意识不强等问 题。本文通过对全国本专科院校 10000 余名师生进行调研, 分析了新形势下高校大学生安全教育状况, 并总结 出现阶段高校安全教育存在的问题，提出解决问题的对策与建议，期望能切实提高对大学生安全教育的成效。 关键词: 高校大学生; 安全教育; 现状调查; 对策与建议 


\section{1. 前言}

近代美国心理学家马斯洛提出的“人类需求层次 理论”认为, 人类社会是一个追求安全机制的有机体, 寻求安全感是人类追求更高层次需求的基础, 是构筑 人类幸福心理金字塔的塔基 ${ }^{[1]}$ 。国家安全、社会安全 和个人安全是人类社会良性运转的的基础性需求, 高 校作为青年大学生聚焦的场所、人才培养的摇篮, 校 园安全稳定和大学生人生与思想的安全维系着国家 与社会的稳定。因此, 高校的安全稳定工作历来受到 党中

央、国务院的高度重视和全社会的极大关注。另 一方面, 建设安全、稳定、和谐的校园文化是构建和 谐社会、弘扬社会主义核心价值观的重要组成部分, 也是确保高校各项教学科研工作顺利开展的基础保 障。

校园安全的重中之重是确保师生人身、财产与意 识形态的安全。基于此, 本项目研究的立足点在于就 以上三个方面的内容对当前高校校园安全状况进行 问卷调查, 并在对调查问卷进行数据统计与分析的基 础上, 为高校改进大学生安全教育提供实施路径参考。

\section{2. 调查思路与方法}

本研究综合运用文献查阅、学习交流、反思总结 等方法凝练高校大学生安全教育问题所关涉的基本 维度, 以此为基础我们针对老师和学生, 精心设计了 高校大学生安全教育状况调查问卷, 主要涉及到四个 方面: 一是对校园总体安全状况的评价; 二是对学校 安全管理方面的评价, 所在学校安全教育教学情况和 大学生安全教育活动与形式; 三是学生自身对安全教 育了解度和关注度; 四是大学生安全素质评价体系等 方面的现实状况。

本次调查采取全面调查方法, 针对不同的调查群 体, 共设计了两类问卷调查, 其中, 学生版问卷调查 先后发放调查问卷 9237 份, 回收并选取有效问卷 9237 份, 教师版问卷调查先后发放调查问卷 424 份, 回收并选取有效问卷 424 份, 回收率 100\%。主要涉 及“双一流高校”“211”“985”院校、普通本科院校、民 办本科院校、高职院校; 本科学生、大专学生、研究 生、博士等不同层次、不同专业和类别高校的学生和 教师。

\section{3. 调查结果与数据分析}

\section{1. 对校园总体安全状况的调查情况}

根据问卷调查的结果，如图 1、2 所示，综合现 有文献的归纳, 结合访谈, 本文认为和大学生日常校 园学习生活联系较为紧密的安全问题主要有: 人身与 财产安全、交通安全、生活与交往安全、心理健康安 全、信息与网络安全等。

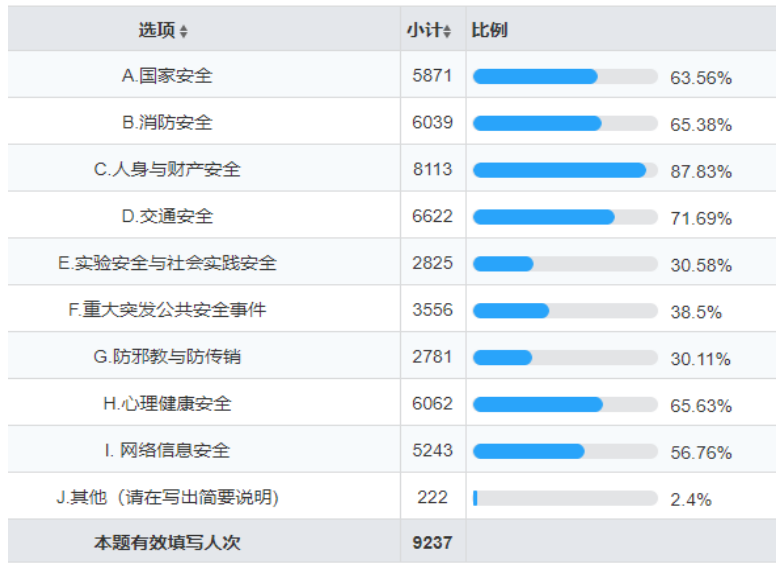

图 1 大学学习和生活中经常遇到的或经常关注的安 全问题

\begin{tabular}{|c|c|c|c|}
\hline 选项 今 & 小计ث & 比例 & \\
\hline A.盗得 & 5496 & $\longrightarrow$ & $59.5 \%$ \\
\hline B.宿舍火灾 & 4810 & 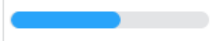 & $52.07 \%$ \\
\hline C.宿舍安全用电 & 6053 & 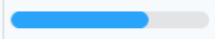 & $65.53 \%$ \\
\hline D. 诈骗 & 6957 & $\longrightarrow$ & $75.32 \%$ \\
\hline E. 传销 & 4653 & 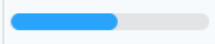 & $50.37 \%$ \\
\hline F. 非法小额贷款 & 4590 & $\longrightarrow$ & $49.69 \%$ \\
\hline G.出行交通安全 & 3620 & $\longrightarrow$ & $39.19 \%$ \\
\hline H.性骚扰、性侵害 & 2917 & $\longrightarrow$ & $31.58 \%$ \\
\hline I. 其他（请在写出简要说明） & 147 & 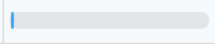 & $1.59 \%$ \\
\hline 本题有效填写人次 & 9237 & & \\
\hline
\end{tabular}

图 2 大学生最容易遭受的安全威胁

\section{2. 对学校安全管理方面的调查情况}

在调查分析大学生安全意识时, 本文从两个层面 开展, 一是大学生安全教育教学情况, 二是大学生安 全教育的活动与形式。

\section{2. 1. 大学生安全教育教学情况}

针对大学生的安全教育教学情况, 我们不仅面向 学生进行调查, 还对教师进行了相关调查, 发现大部 分学校 $(88.08 \%)$ 都开设了安全教育课, 有的学校甚 至将安全教育课纳入必修课和人才培养方案。但是大 部分学校的安全教育课的学时都不是很多, 缺乏较完 善的安全教育课理论体系及模拟操作能力, 专业性不 强, 不能全方面全覆盖的让安全教育知识入学生的脑、 入其心。

\section{2. 2. 大学生安全教育的活动与形式}

通过对教师和学生的问卷调查和个人访谈, 调查 发现（如下图）, 高校开展大学生安全教育的活动与 形式大部分停留在理论宣讲和传统的“灌输多、互动 少”的安全教育形式, 这与学生说需求的实际演练的 
安全教育活动方式还存在一点距离, 也不利于学生安 全技能的掌握和安全素质的培养。

\begin{tabular}{|c|c|c|}
\hline 选项 & 小计今 比例 & $88.08 \%$ \\
\hline A.是 & 8136 & $3.56 \%$ \\
\hline B.否 & 329 & $8.36 \%$ \\
\hline C.不知道 & 772 & \\
\hline 本题有效填马人次 & 9237 & \\
\hline
\end{tabular}

图 3 除安全教育课外, 学生在校期间参加的安全教 育活动的次数

\begin{tabular}{|c|c|c|c|}
\hline 选项 & 小计今 & 比例 & \\
\hline A.开展安全讲座 & 8498 & $\longrightarrow$ & $92 \%$ \\
\hline B.校园宣传栏、黑板报 & 7147 & $\longrightarrow$ & $77.37 \%$ \\
\hline C. 发放宣传单 & 4389 & $\longrightarrow$ & $47.52 \%$ \\
\hline D. 实践演练 & 4834 & $\longrightarrow$ & $52.33 \%$ \\
\hline E.安全知识小竞赛 & 5164 & $\longrightarrow$ & $55.91 \%$ \\
\hline F.影德观摩 & 3209 & $\infty$ & $34.74 \%$ \\
\hline G.安全教育图片展 & 3496 & $\longrightarrow$ & $37.85 \%$ \\
\hline H. 组织安全教育网络课程学习 & 4212 & $\longrightarrow$ & $45.6 \%$ \\
\hline I. 其他 (请写出简要说明) & 188 & 1 & $2.04 \%$ \\
\hline 本题有效填与人次 & 9237 & & \\
\hline
\end{tabular}

图 4 学校开展安全教育活动的形式

\begin{tabular}{|c|c|c|}
\hline 选页 & 小it) & 比例 \\
\hline A.安全理论知识灌输 & 394 & $92.92 \%$ \\
\hline B.安全榁例展示分析 & 392 & $92.45 \%$ \\
\hline C.现场勘率安全问题 & 209 & $49.29 \%$ \\
\hline D. 头脑风暴交流研讨 & 144 & $33.96 \%$ \\
\hline E、粯披安全操作演练 & 273 & $64.39 \%$ \\
\hline 本题有效嫃与人次 & 424 & \\
\hline
\end{tabular}

图 5 学校开展安全教育活动的形式

\section{3. 学生自身对安全教育了解度和关注度的 调查结果}

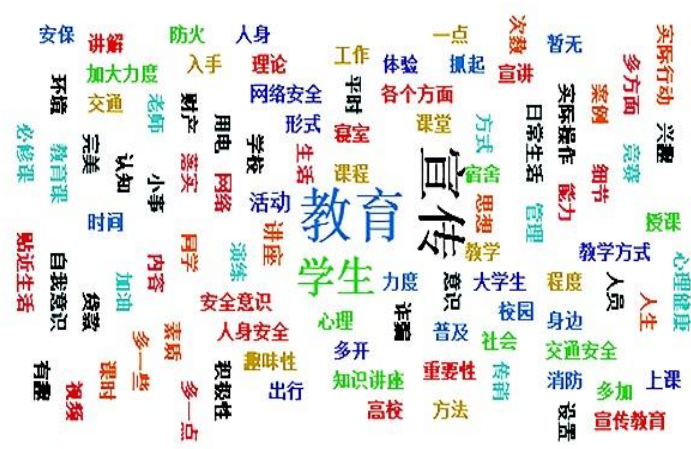

图 6 大学生安全教育关注点词云
通过调查结果与词频分析, 学生认为高校应该从 安全教育本身、安全教育宣传和安全教育主体三个方 面进一步改善大学生安全教育教学。

然而, 调查数据显示大学生对于其身处其中的校 园安全意识较浓, 但却对实践却偏离安全意识的行为 不以为然。他们的安全意识大多存在于被动接受的灌 输状态, 并不能够将安全意识落到日常生活中, 在安 全防范的实践方面仍然相对较弱, 没有形成意识与行 动统一的良好安全习惯。因而高校的保卫处所受理的 关于安全类的案件还是很多。

\section{4. 大学生安全素质评价体系}

针对大学生安全素质评价体系, 本文主要从大学 生安全教育工作方案、大学生安全教育工作体系、大 学生安全教育研究机构、大学生网络安全线上平台等 方面展开调查, 调查对象主要是各高校教师。

\section{4. 1. 大学生安全教育工作方案}

本文针对其他高校教师进行了专项调研: 您所在 的学校是否在校级层面出台并实施了大学生安全教 育工作方案? 如下图所示, $66.27 \%$ 的高校已出台且成 效显著, 但仍有 $4.48 \%$ 的高校未出台相关的教育工作 方案, 说明大部分高校都比较重视大学生安全教育工 作, 并采取了相对应的措施, 取得了一些实效。

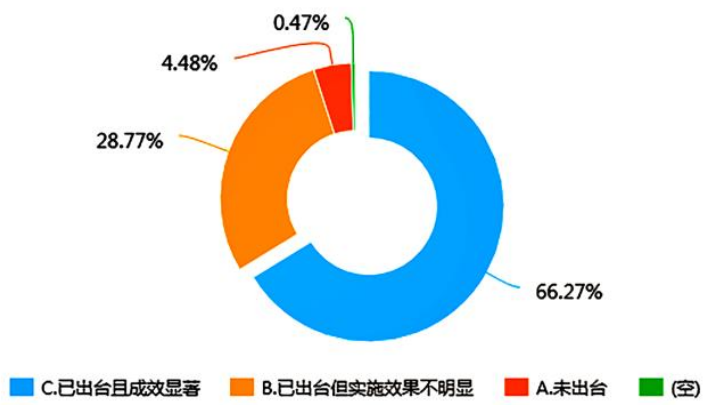

图 7 大学生安全教育工作方案实施情况

\section{4. 2. 大学生安全教育工作体系}

本文通过调查发现, 关于大学生协同安全教育与 管理工作体系, 受调查的学校中, 有 $52.12 \%$ 已建立但 是实施程度有待进一步完善, $5.66 \%$ 尚未建立但在尝 试建立, $4.25 \%$ 未建立, 安全教育和管理零散单一, 实施成效低。可见关于大学生协同安全教育与管理工 作体系, 还需进一步加强重视, 不断改进和完善结合 当代学生特点的安全教育体系。

\section{4. 3. 大学生安全教育研究机构}

针对大学生安全教育研究机构, 如下图 8 所示, $60 \%$ 以上的都未成立研究机构, 即使成立了研究机构, 专项研究零骞无几。 


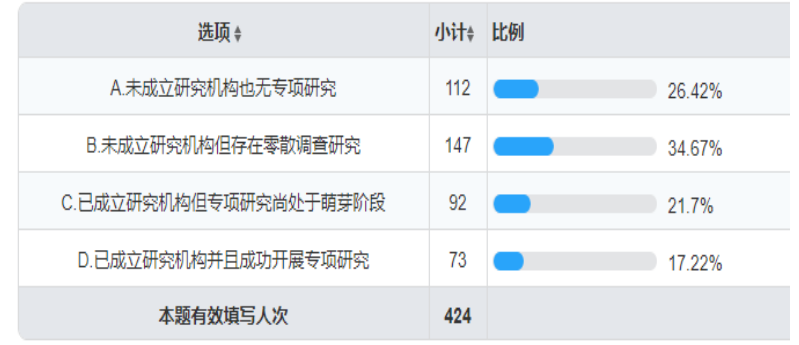

图 8 大学生安全教育研究机构成立情况

\section{4. 4. 大学生网络安全线上平台}

有关安全教育网络在线学习平台的调研显示 $67.22 \%$ 的高校没有建立相对应的线上学习平台, 仅有 $22.41 \%$ 的高校建有平台, 并能够按照要求定时参加系 统学习。说明在线上平台或学习资源库这块, 大部分 学校还不是很健全, 体系还不完善。

\section{4. 高校普通存在安全教育问题}

通过调研, 总结出新形势下高校的安全教育存在 的问题主要有:

\section{1. 校园周边治安环境复杂}

各地普遍重视高校的建设和发展, 在高校周边配 套有较好的生活和服务场所, 方便高校师生的学习和 生活。因此, 高校周边也形成了一定规模的商业消费 场所, 如餐厅、网吧、理发店、超市、商场或者休息 娱乐场所等。这些场所一般人空间有限、人流密集, 消防隐患较大, 加之社会闲散人员混杂其间, 治安问 题漏洞较多。其次, 校外无证商贩的无序销售, 在一 定程度上影响了学生的学习和休息。再次, 校园周边 交通问题。一般高校所在区域要么为繁华闹市区, 要 么以高校为中心向外辐散, 人车混行, 交通隐患大。

\section{2. 尚未建立科学有效的大学生安全教育体} 系

在调查中, 反馈出高等学校大学生安全教育以 “管”为主、以“教”为辅, 对安全教育重视和落实不足。 高校缺乏对大学生安全教育的整体顶层规划, 多未建 立全校统筹的大学生安全教育体系。在安全管理上, 校外公安机关、学校保卫处、学生工作部门、二级学 院之间的安全教育管理资源缺乏有效的统筹, 存在着 各自运行、协同互动不足的问题。在教育上实施上, 缺乏融入人才培养方案的全面设计。在教育人员上, 存在着专业化程度不高等问题。在教育载体上, 多数 学校未建立专业安全教育数字化平台, 未实现安全教 育资源的数字化改造。在安全教育实践中, 存在着随 意性强，规范性不足等问题。
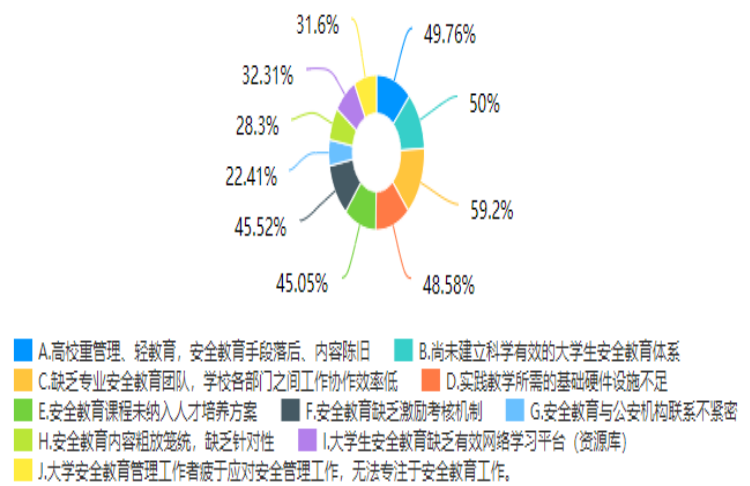

图 9 当前大学生安全教育的主要问题

\section{3. 大学生安全自育自省自防能力不强}

调查发现，随着 00 后大学生步入大学校园，大 学生的安全意识普遍比较薄弱, 打架、交通碰撞、火 灾、奢博等校园治安案件也时有发生, 新型网络骗局、 网络借贷等案件时有发生在大学生身上。集中反映了 部分大学生安全常识的缺乏、安全教育的不足和安全 防卫手段的贵乏。

\section{5. 调查结论与建议}

促进大学校园保持安全稳定的因素很多, 但人的 安全意识是最重要的因素。因而, 如何增强大学校园 教职员工和广大学生的与安全意识是做好校园安全 工作的首要前提。本文针对调研中发现的问题, 提出 了三个方面的对策建议。

\section{1. 升级校园安全管理效能, 打牢校内安全稳 定基础}

\section{1. 1. 协同治理校园周边环境, 营造平安和谐 社区环境}

大学校园是一个与校园周边社区相互融合、相互 影响的共同体, 高校需要和学校所在街道的政府机构、 公安机关、城管单位、社区一道，共同努力做好校内 外的综合治理, 为大学校园的周边治安环境的美好, 发挥好各方协同、防范未然的作用。在校园内部安全 治理上, 要建强安全教育和管理的队伍, 发挥好以安 全教育课堂这一第一课堂主渠道的作用, 强化大学生 的安全意识和安全防范能力。发挥好安全保卫人员、 辅导员等安全管理人员的作用, 及时发现和处置各类 安全问题，将安全事故化解在萌芽阶段。

\section{1. 2. 强化校园安全法制意识, 依法完善安全 教育制度}

全面依法治国是我国四个全面战略布局的重要 一环, 高校贯彻落实依法治国的战略, 就是要依法治 校。大学生安全教育也需要遵循这一要求, 做到依法 
治安。因此, 大学生安全教育需要学校在制度上贯彻 落实党和国家安全教育的法律和法规, 并结合学校的 实际, 编制适用于学校的安全教育的各项安全教育的 规定，形成大学生安全教育的制度体系，辅以全校师 生的高度认同和认真遵守, 必将取得良好的安全教育 效果。

\section{1. 3. 保障安全教育的必要投入，创设安全教 育空间载体}

新时代的大学生安全教育需要有能唤起大学生 安全教育自觉的新模式和新载体。当前, 大数据、人 工智能、虚拟仿真技术已经充分融入了大学教育。高 校也可以运用必要的技术手段, 在校内创设大学生安 全教育基地, 增设一定数量的安全教育警示、互动体 验的项目, 帮助学生能不到安全事故现场、不出校门 就能感受到安全事故的震撼警示教育效果。同时，高 校还可以运用现代安防技术, 实现对校院重点单位、 重点场所的技术性监控, 运用网格化和大数据技术实 现对大学生的安全情况的“画像”，充分发挥好技术对 安全教育和管理的促进作用。这些, 均需要高校拿出 一批资金和人员, 给予大学生安全教育的升级充分必 要的投入。

\section{2. 优化大学生安全教育生态, 完善安全教育 体系}

\subsection{1. 优化大学生安全教育生态，构建 “课堂 十信息技术十实践活动”的安全教育方式}

高校应以青年学生喜闻乐见的方式开展安全教 育活动, 搭建“课堂+信息技术+实践活动”的安全教育 方式, 在充分发挥课堂教学主渠道作用的同时, 积极 运用现代信息技术、依托课程教学、专题教育、团学 组织及社团活动, 以实操演练为抓手, 打造形式多样、 全覆盖、持续性的有效安全教育。

一是除了开设安全教育课之外, 还应与信息化手 段相结合, 将安全教育前置到学生进入大学前, 并将 该课程纳入人才培养方案 ${ }^{[2]}$ 。同时, 优化教师队伍, 专业人做专业事, 请公安警察、保卫处工作人员等进 课堂。二是组织安全教育知识竞赛等多种形式的安全 教育活动, 搭建点面结合、线上线下结合, 课程与活 动结合, 师生互动的安全教育平台, 并使之有效运转。 三是教育教学和安全实践紧密相连, 加强生活安全管 理, 并纳入大学生日常考勤考核中评比。

\subsection{2. 以信息技术为基础构建高校 “三进” 安 全教育体系}

随着网络信息技术的飞速发展，社会的价值观念 呈现多元化特征。安全教育需要从传统学校教育的 “进教材、进课堂、进学分”的安全教育体系向安全教 育“数字化、安全意识立体化、安全案例生活化”的方
向转变。在借鉴传统校园安全教育方式的基础上，本 文提出了以下安全教育模式改革的思路:

一是安全教育必修课, 安全警示案例教材化。二 是建立安全教育课程体系和网络教育体系, 储备具备 大数据处理能力的专业的安全教育教师团队, 配备专 职教师讲授课程, 从安全意识、师资队伍、教研设备、 教学研讨等多方面予以保障。三是落实安全教育“进 学分”的工作要求, 帮助学生树立安全第一的人生理 念。四是建立体验式模拟仿真安全警示教育实践教学 基地, 将校园安全案例进行数字化编排处理, 增加实 践环节教育教学课时。

\subsection{3. 建立专业安全教育团队，加强多方协同， 形成联动机制}

安全教育工作是一项涉及政府、高校和个体的系 统工程, 需要统筹协作, 整合资源, 形成联动机制, 以达到齐抓共管，从而提高安全教育实效性。

首先，高校应充分整合社会资与社会各组织、机 构形成联动机制。加强学校、上级教育主管机构、公 安、消防等各单位间的联系，发挥现有制度体系中各 组织所具备的经验优势, 形成合力作用于学校的安全 教育体系。

其次, 校园安全管理需置于整个社会安全管理范 畴之中。校园警务安全可与公安机关实时联动, 以社 会警情预警校园安全, 以公安机关的强制手段化解校 园潜在安全隐患, 以法律为准绳, 威慑与预防相结合, 安内阻外, 提高大学生的安全防范意识 ${ }^{[3]}$ 。

最后, 高校通过各类渠道不断加强学生的安全意 识, 学生本人也要提高各方面的安全意识, 自觉树立 安全意识, 维护校内外安全, 提升处置安全问题的能 力。

\section{3. 强化大学生安全责任, 防范化解风险于未 然}

\section{3. 1. 激发大学生安全防范自觉}

高校需要注重发挥好受教育者一大学生本人 在安全教育中的主观能动性。通过教育和管理有效唤 醒和激发大学生本人在安全教育中的作用, 增强大学 生法律意识和防范能力, 通过大学生自身的安全知识 储备和安全实践经验去评估风险、化解危机。

\subsection{2. 关注大学生的安全心理建设}

安全教育中有一个非常重要的内容就是安全健 康教育。高校可以在大学生心理健康教育课程或者安 全教育课程中, 安排设置安全健康教育的专题, 教授 学生必要的心理安全建设的方法, 帮助学生可以在逆 境或者危险情形下实现自我激励和调节，疏导心理， 抗压化解矛盾和困难, 减少安全问题的产生 ${ }^{[4]}$ 。其次, 
高校可以通过心理健康教育中心、辅导员和学生干部, 帮助心理安全有障碍的学生构建积极的心理安全支 持系统, 帮助学生能内心不安全的心理和行动状态中 转移出来。

\section{3. 3. 培养大学生的安全防范能力}

高校可以在专业人才培养方案中, 专门设置安全 教育课程, 将大学生安全教育划分成人身安全、财产 安全、交通安全、消防安全、食品安全等不同的内容 模块, 通过专门课程的方式对全体学生进行系统全面 的讲解。在安全教育实践中, 通过组织学生前往校内 外安全教育基地、观摩体验安全事故 (模拟) 现场等, 让学生获得直观感受, 形成安全防范的基本认知, 从 而形成安全防范的能力。

\section{项目基金}

本文为湖北省规划办重大招标课题《高校大学生 安全教育的理论与实践研究》(立项编号 2018ZDZB15) 的阶段性成果之一。

\section{REFERENCES}

[1] Ma M, Wang S.H. (2019) A Survey of College Students' safety Consciousness -A Case study of Colleges and universities in Beijing.Journal of Heilongjiang Institute of Political and Legal Management. pp. 157-160.

[2] Zhou,X.S. (2017) Research on the problems and countermeasures of college students' safety education. Wuhan Polytechnic University. Wuhan. pp.12.

[3] Cheng S.M. (2014) Research on the Improvement of College students' safety quality from the perspective of risk society. Capital Normal University. Beijing. pp14.

[4] Lei L. (2016) Study on the influencing factors and countermeasures of college security and stability. Nanchang university. Nanchang. Pp20. 